\title{
SPECIFICITY OF INTERMOLECULAR ACTION IN SYSTEMS INCLUDING POLYELECTROLYTES AND IONS OF ORGANIC PHYSIOLOGICALLY ACTIVE SUBSTANCES
}

\author{
G. V. SAMSONOV \\ Institute of High Molecular Compounds \\ Academy of Sciences of the USSR \\ Leningrad, USSR
}

\begin{abstract}
Thermodynamic analysis of the sorption laws of quaternary ammonium bases with aromatic and aliphatic radicals, of other organic bases and organic acids, and ions of antibiotics in particular, has shown that a combination of electrovalency interaction and weak interaction plays a decisive part in the specificity of interaction. This combination depends both on the polyelectrolyte structure and on properties of organic counterions. The increase in the entropy of the system during sorption of a number of complex organic ions, the existence of the compensation effect of enthalpy and entropy for many systems may be interpreted as a coexistence of a multiplet additional interaction, i.e. the occurrence of a comparatively large number of microstates for each ion bound with a polyelectrolyte, or as the hydrophobic effect. It is quite probable that both effects are operative.

In the systems under investigation an additional interaction becomes apparent as a cooperative effect which is revealed by an increase in the free energy of bonding with the increase in the quantity of organic ions bound with polyelectrolyte.

The introduction of large amounts of organic substances into a polyclectrolyte gel changes the dielectric propertics of the medium and shifts the usual electrovalent interactions. Thus, in cation exchangers, a shift of the hydrogen-sodium exchange occurs and the organic ion-sodium binary system is gradually transformed into the organic ion-sodium-hydrogen ternary system. Sorption of bipolar ions (amino acid proteins) also occurs with electrochemical recombination of sorbate, i.e. its protonation.

A study of the interaction of amino acids, polypeptides and proteins, especially enzymes, with carboxylic cation exchangers, enabled us to predict the necessary structures of crosslinked polyelectrolytes for reversible specific high capacity sorption of many enzymes. A new class of carboxylic cation exchangers 'Biosorb' has been synthesized and with their aid many proteases, pectinases, amylases and other enzymes have been isolated and purified. Thus, the microbe protease was completely separated from amylase of almost the same molecular weight with a close isoelectric point. The process is carried out at a very high enzyme-sorbent ratio exceeding by several hundred times the corresponding value for gel filtration. The columns are only 3 to $5 \mathrm{~cm}$ high.
\end{abstract}

A unique feature of the new group of crosslinked carboxylic polyelectrolytes 


\section{G. V. SAMSONOV}

is the combination of high permeability, low variation of hydration with changing $\mathrm{pH}$ of the medium and high selectivity of the sorption of organic ions. Separation with the aid of these gel sorbents is determined by the molecular weight of the proteins and by their electrochemical properties including isoelectric points and local bipolarity.

A special class of systems includes interacting soluble polyelectrolytes, in particular linear polyelectrolytes and ions of organic physiologically active substances. Under certain conditions, the modification of biopolymers, such as enzymes or protein hormones, which takes place in these interactions leads to stabilization of their structure, maintenance, inhibition or increase of biological activity and shows paths for synthesizing new drugs. A method for protecting insulin from the action of proteolytic enzymes and of acid medium with retention of hormonal activity is based on these principles. A systematic investigation of the interaction of pancreatic ribonuclease with polyelectrolytes in solution led to preparation of stabilized and activated enzymes or to inhibition of nuclease. Not only the structure of the polymer support, but also its molecular weight is of great importance for the different effects on nuclease. The cooperative effect of intermolecular interaction contributes to the effect of inhibition whereas random interaction favours the effect of enzyme activation.

Preparation and study of crosslinked and soluble polyelectrolytes specifically binding ions of organic physiologically active compounds, such as antibiotics, hormones, enzymes or alkaloids is of considerable interest in connection with methods of separation and fine purification of these compounds as well as their modification and stabilization. It is also important to analyse theoretically general relationships governing the behaviour of supermolecular biologically active polyelectrolytic systems.

While considering ion exchange systems including ions of organic substances of a relatively low molecular weight, the sorption phenomena for quaternary ammonium bases, antibiotics and to a certain extent alkaloids have been studied in greatest detail. When the interaction of synthetic polyelectrolytes with biopolymers was investigated, the greatest attention was directed to the binding of proteins, in particular enzymes.

\section{PRINCIPLES OF ION EXCHANGE SORPTION OF QUATERNARY AMMONIUM BASES AND ANTIBIOTICS}

Many essential principles of the intermolecular action of complex ions of physiologically active substances with linear and crosslinked polyelectrolytes are observed in the sorption of ions of quaternary ammonium bases on ion exchange resins ${ }^{1-9}$. These systems may be considered as model substances although they themselves are of interest, e.g in investigating the mechanism of action of some psychotropic preparations.

Various antibiotics were considered as the next group of more complex organic ions. It was taken into account that in accordance with their degree of complexity they resemble either simple symmetric ions or more complicated ions with many functional groups ${ }^{10-22}$. It should be noted, however, that ion exchange sorption of antibiotics is of great practical importance 
SPECIFICITY OF INTERMOLECULAR ACTION

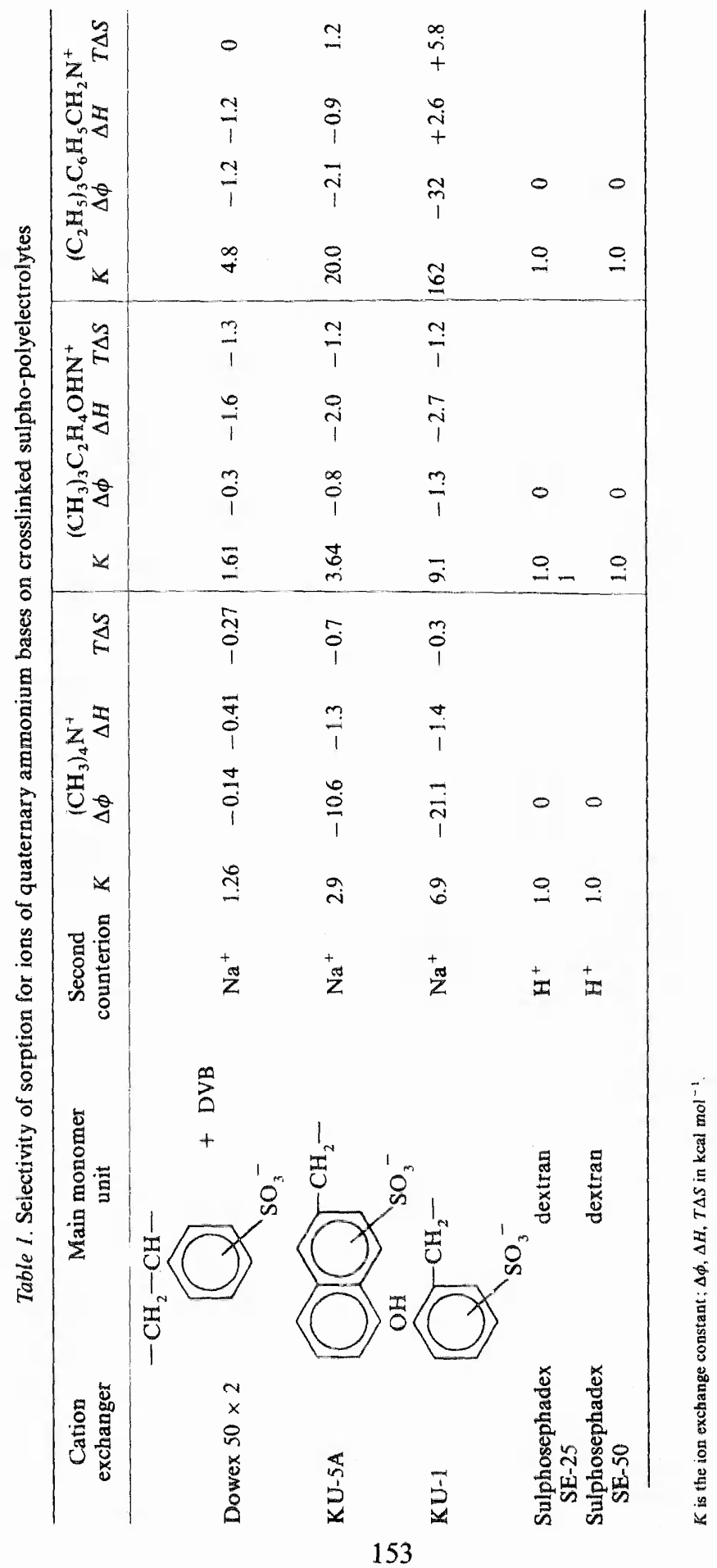


for developing industrial methods of separation and purification of these physiologically active substances.

We shall consider the relationships of ion exchange with participation of quaternary ammonium bases taking into account the complex structure of these ions and the peculiarities of the structure of crosslinked polyelectrolytes. Table 1 shows thermodynamic constants of ion exchange characterizing the selectivity of sorption of these ions in their competition with sodium or hydrogen ions. The latter two types of ions exhibit more or less the same affinity for the investigated sulpho cation exchangers. For the first three cation exchangers the selectivity of sorption increases in the following order tetramethylammonium, trimethyloxyethylammonium, trimethylbenzylammonium. The introduction of a polar hydroxyethyl group and of a still more polar benzyl group which are capable of additional interaction with ion exchangers on the basis of a dipole-dipole interaction or some other type of interaction increases the specificity of the binding of ions of quaternary ammonium bases. The increase in the complexity of structure of crosslinked polyelectrolyte also leads to similar results. The replacement of a benzene ring by a naphthalene ring or the appearance of a phenyl radical (i.e. the introduction of groups increasing additional interaction with radicals with sorbed ions) leads to a considerable increase in the selectivity of sorption of organic ions. In this connection we should point out the extremely low selectivity of sorption for all ions of quaternary ammonium bases on sulphoSephadexes. It is well known that in the absence of ionogenic groups the matrices of these gels interact very slightly with organic ions. This peculiarity was used for the devalopment of gel chromatography in which a weak reversible interaction is observed (for example with ions of biopolymers), and substances are separated according to their molecular volumes with a very small effect from their functional groups on their interaction with Sephadexes.

Table 2. Selectivity of ion exchange sorption of antibiotics

\begin{tabular}{llccc}
\hline \multicolumn{1}{c}{ Counterions } & Ion exchanger & $\Delta \phi$ & $\Delta H$ & $T \Delta S$ \\
\hline Penicillin chlorine & FAF & 5.5 & 10.0 & 11.0 \\
Erythromycin-sodium & KFUKh & 60.0 & 3.5 & 5.9 \\
Chlorotetracycline-sodium & SBS & 123 & 1.7 & 4.4 \\
Oxytetracycline-sodium & SBS & 148 & -3.6 & -0.77 \\
Novobiocyn-chlorine & FAF & 950 & 4.0 & 8.3 \\
\hline
\end{tabular}

$\Delta \phi, \Delta H, T \Lambda S$ in $\mathrm{kcal} \mathrm{mol}^{-1}$.

In considering thermodynamic functions in this phenomenon of ion exchange it is of particular interest that the positive entropy sign appears for systems with the highest selectivity of organic ion sorption. As a rule, ions of antibiotics, which are of much more complex structure, are sorbed by a mechanism leading to an increase in entropy (Table 2).

Coming back to the problem of participation of the matrix of synthetic polyelectrolyte in the formation of additional bonds with organic ions, we shall consider the influence of ionogenic and non-ionogenic monomers on the selectivity of sorption. Figure 1 shows the thermodynamic constant of the ion exchange of ions of quaternary ammonium bases with hydrogen 


\section{SPECIFICITY OF INTERMOLECULAR ACTION}

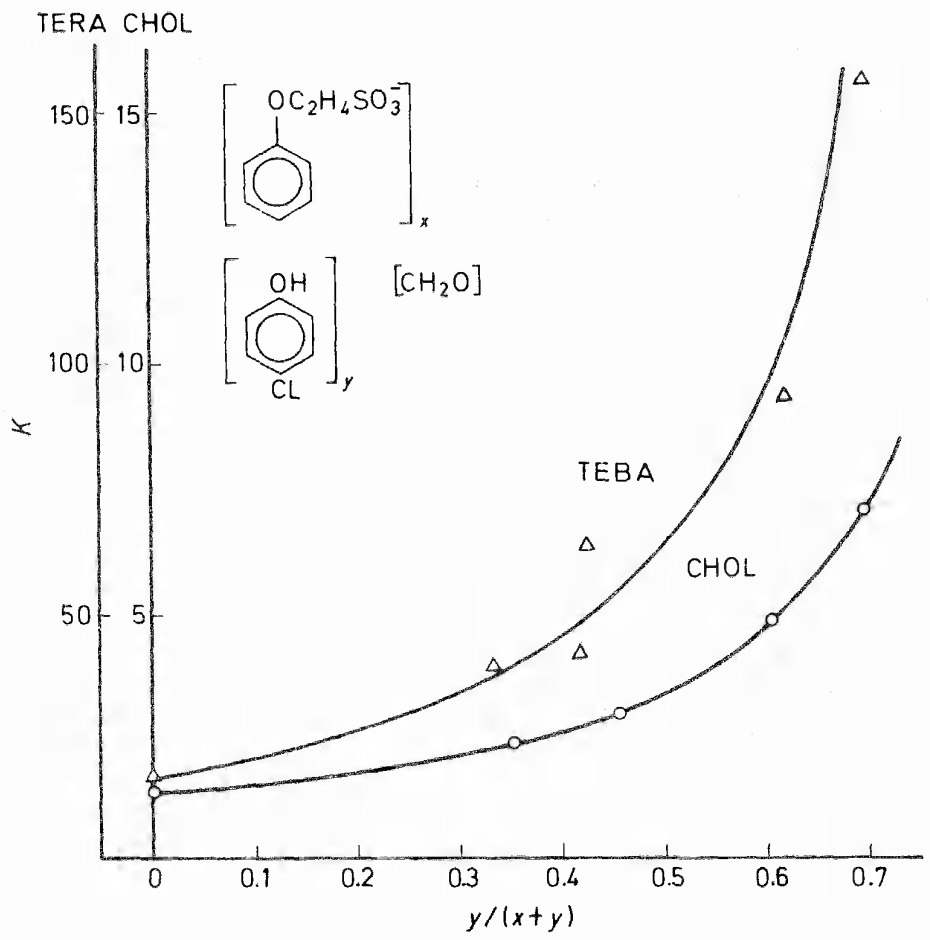

Figure 1. Effect of monomer ratio in the resin on the sorption selectivity of quaternary ammonium ions. TEB $\mathrm{A}-\left(\mathrm{C}_{2} \mathrm{H}_{5}\right)_{3} \mathrm{CH}_{2} \mathrm{C}_{6} \mathrm{H}_{5} \mathrm{~N}^{+} ; \quad \mathrm{CHOL}-\left(\mathrm{CH}_{3}\right)_{3} \mathrm{C}_{2} \mathrm{H}_{4} \mathrm{OHN}^{+} . \quad \mathrm{K}=\left\{\begin{array}{c}x=1 \\ x=0\end{array} K_{5} \mathrm{~d} x\right.$;

$$
K_{\mathrm{s}}=m_{\mathrm{org}} C_{\mathrm{H}} / m_{\mathrm{H}} C_{\mathrm{org}}
$$

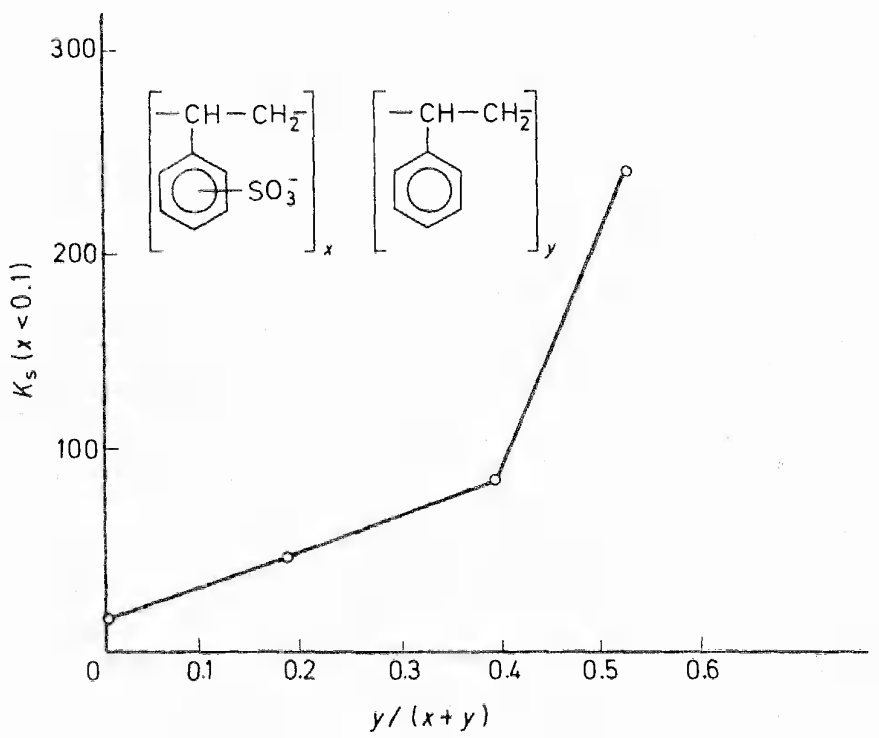

Figure 2. Effect of the degree of desulphonation of sulpho cation exchanger on the selectivity of ion exchange sorption of oxytetracycline. The second counterion is hydrogen. 
ions versus the content of non-ionogenic monomers ( $p$-chlorophenol in acid solutions used in the experiment was not ionized). In both systems the selectivity of sorption markedly increases with decreasing content of ionogenic groups. The selectivity increases especially sharply when the molar fraction of non-ionogenic groups exceeds 0.5. A similar phenomenon was observed in the sorption of oxytetracycline on partly desulphonated exchangers of the type of Dowex-50 (Figure 2). The increase in the content of desulphonated monomers in the exchanger leads to a drastic increase in the selectivity of sorption of antibiotics.

The increased selectivity of sorption related to the hydrophobization of polyelectrolyte and the simultaneous increase in the entropy of the system suggests that in some systems including organic ions and polyelectrolytes an additional hydrophobic interaction may play a certain part. Indeed, Figure 3 shows that when substances capable of destroying the aqueous

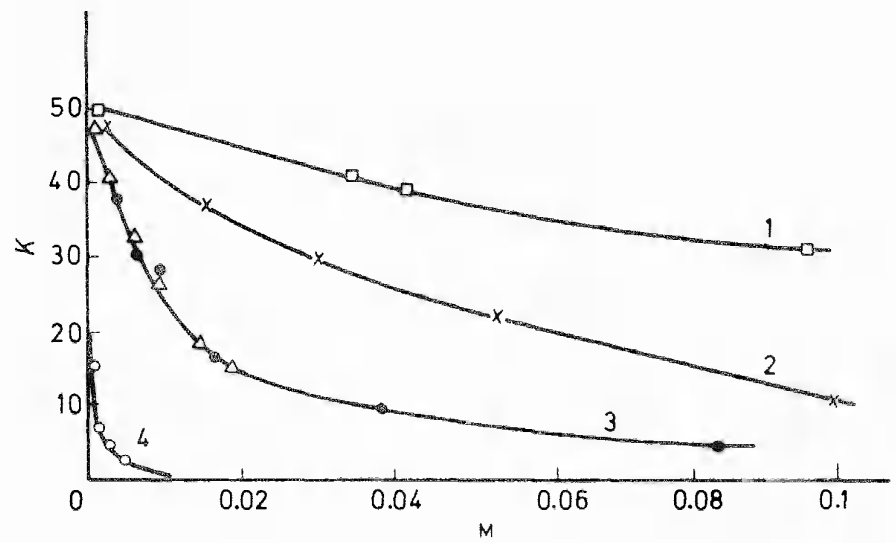

Figure 3. Changes in ion exchange constant with decrease in hydrophobic interaction of oxytetracycline (Dowex-50). $M$ is the molar fraction of the component introduced into the solution. 1 Methanol; 2 ethanol; 3 butanol-urea; 4 sodium dodecylsulphate (the second counterion is hydrogen).

structure are introduced into the solution, the sorption selectivity of, for example, oxytetracycline ions falls markedly.

At the same time the increase in the selectivity of the course of additional interaction of organic ions with polyelectrolytes and the increase in the entropy of the system were found to be very widely spread and were observed even in the sorption of substances with a very low ability of rearranging the water structure. In this connection it became necessary to consider an alternative possibility of increasing the entropy of the system and, hence, to investigate a second model concept.

Thermodynamic functions of the ion exchange sorption of organic ions may be compared only for comparable systems (Figures 4-6). The compensation effect of enthalpy and entropy functions is observed both for sorption of various ions of quaternary ammonium bases on one sodium form of sulpho cation exchanger and for exchange of oxytetracycline with hydrogen on sulphostyrene polyelectrolyte with different content of divinyl- 


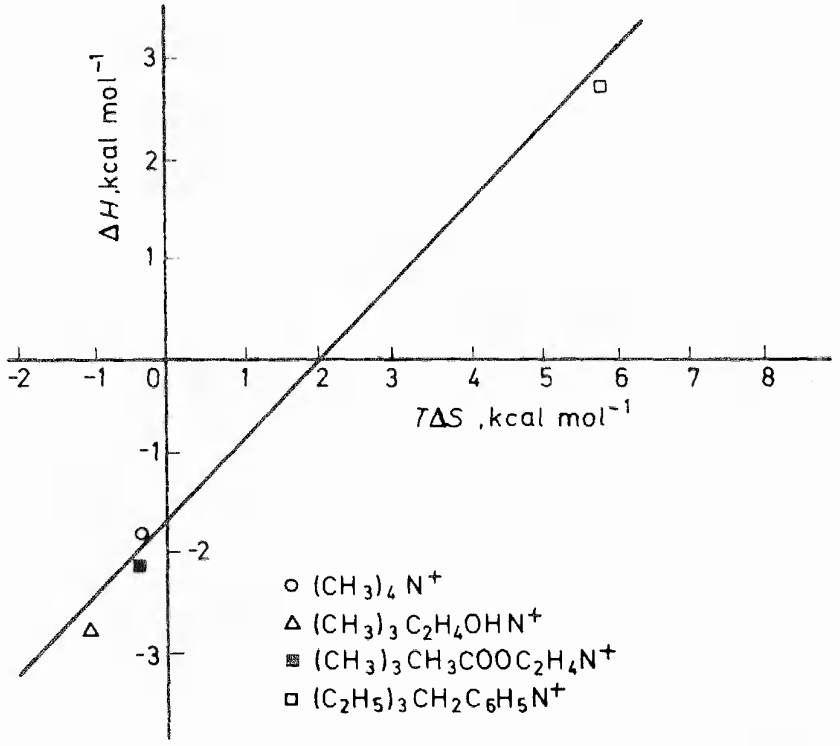

Figure 4. The compensation effect in ion exchange of quaternary ammonium bases on sulphoresin $\mathrm{KU}-1$ (the second counterion is sodium).

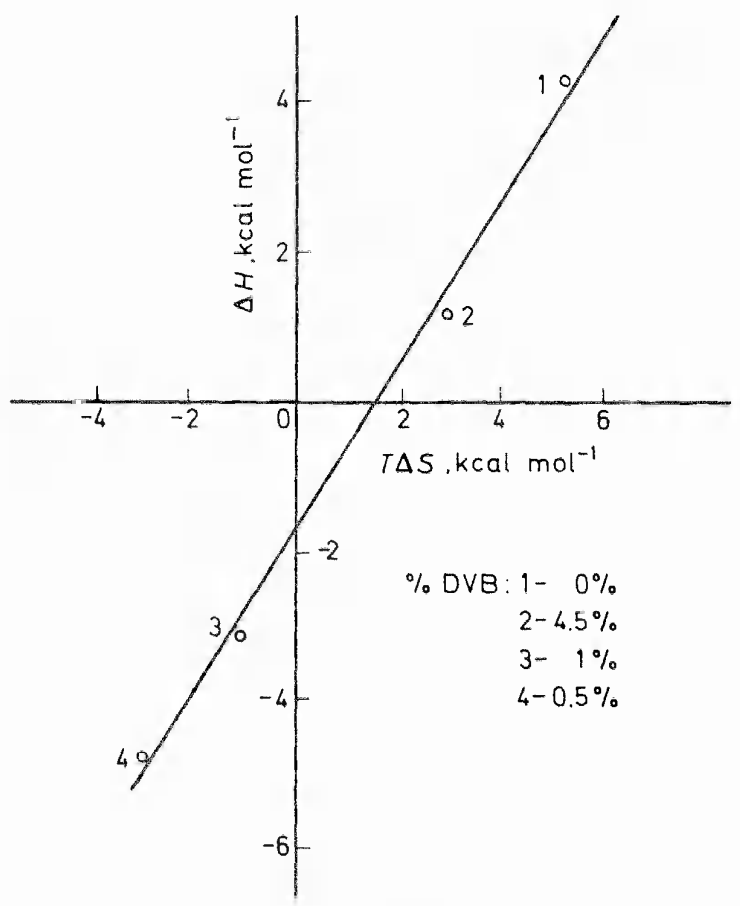

Figure 5. The compensation effect in sorption of oxytetracycline on sulphoresins Dowex -50 with different content of divinylbenzene (the second counterion is hydrogen). 


\section{G. V. SAMSONOV}

benzene (up to its complete absence in a linear polyelectrolyte). A similar phenomenon occurs when erythromycin is sorbed by different cation exchangers (Figure 6). Proceeding from the undoubted importance of additional interactions for the selectivity of sorption of complex organic ions and varying values and even signs of functions of entropy and enthalpy,

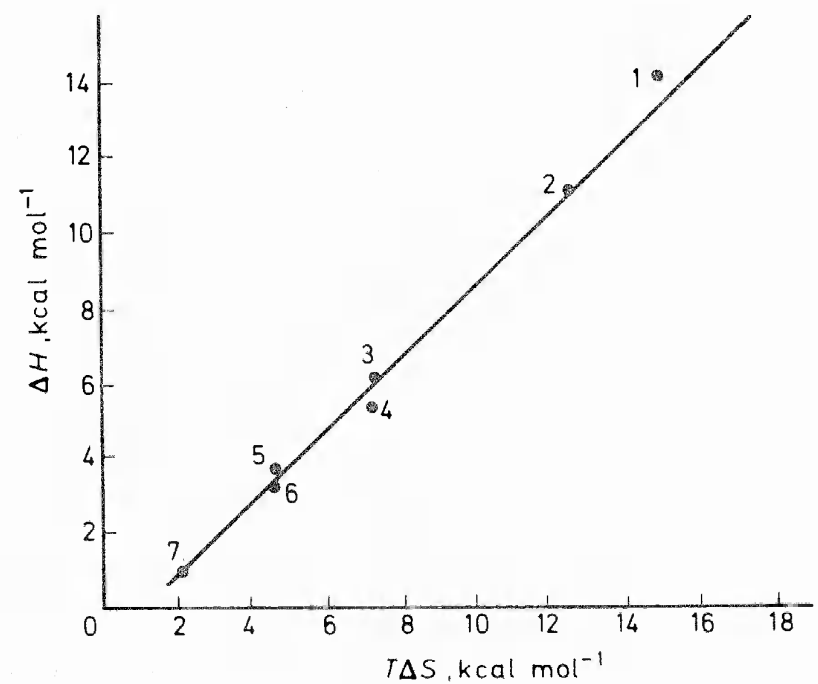

Figure 6. The compensation effect in sorption of erythromycin on different cation exchangers (the second counterion is sodium). 1-Dowex $50 \times 1 ; 2$-Dowex $50 \times 2 ; 3$-Amberlite TRC-50; 4 -KFUKh ; 5-SBS-3;6-KFSKh-3; 7-SBST-3.

it is possible to advance a rational hypothesis that several (sometimes even very many) states exist for the interacting system organic ion-polyelectrolyte in contrast to one microstate for the interaction of ions of hydrogen, sodium or chlorine with the same polyelectrolyte. These microstates occur when the energy of additional interaction leading to the appearance of an additional microstate is neither very low nor very high compared to the energy of thermal motion. When the energy of additional interaction becomes sufficiently high, positive signs of entropy and enthalpy are replaced by negative signs and high selectivity is retained. A considerable decrease in the energy of additional interaction leads to a decrease in the selectivity of sorption of organic ions.

A complex system of molecular interactions is also revealed when we consider the selectivity of sorption of organic ions as a function of their molar ratio in the exchanger. As shown in Figures 7 and 8, we may observe either a decrease in the selectivity of sorption of organic ions due to a gradual exclusion of more active sorption centres or an increase in the selectivity of their sorption, i.e. a cooperative effect consisting of the influence of the sorbed organic ions on the sorption of the following ions. This phenomenon is particularly pronounced in the sorption of oxytetracycline (Figure 8) in which the cooperative effect is observed only when there are many closely spaced ionogenic groups in the exchanger (high exchange capacity and 


\section{SPECIFICITY OF INTERMOLECULAR ACTION}

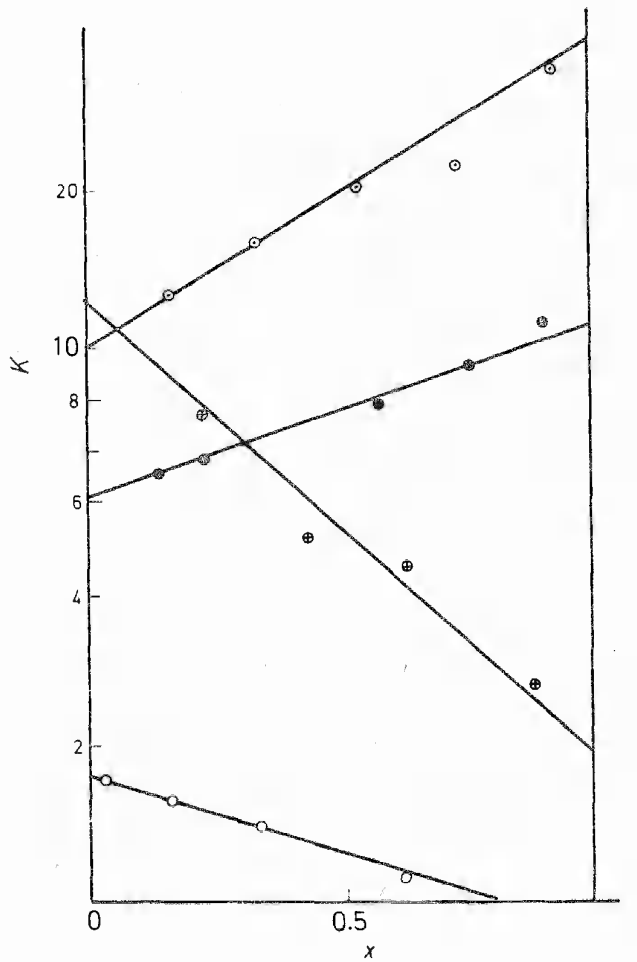

Figure 7. Sorption selectivity of oleandomycin versus its molar ratio in the exchanger $(x) . K$ is the ion exchange constant (the second counterion is sodium).

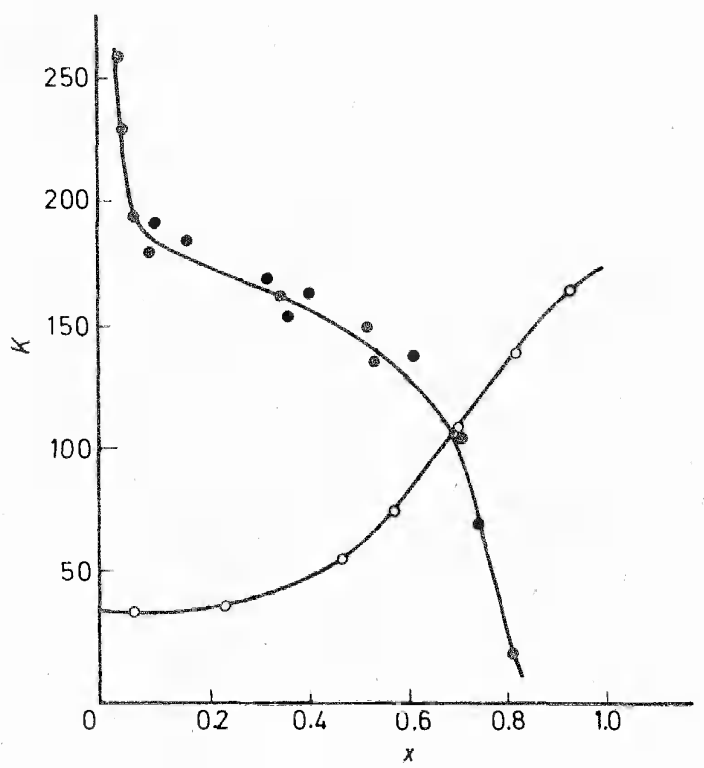

Figure 8 . Soeprion selectivity of oxytetracycline versus its molar ratio in the exchanger $(x)$. The second ion is hydrogen. Dowex-50 $\times 1$, exchange capacity $m_{0}=2.3 \mathrm{meq} \mathrm{g}^{-1} ; \mathrm{O}$, Dowex $50 \times 2$, exchange capacity $m_{0}=5.0 \mathrm{meq}^{-1}$. 


\section{G. V. SAMSONOV}

increased amount of crosslinking agent). An increase in the distance between sol ved ions completely eliminates the cooperative effect. Desulphonated exchanger which is highly selective at a low degree of filling of the exchanger with oxytetracycline cannot compete with an exchanger of high capacity and low selectivity after the sorbed ions exhibit cooperative interaction-when their molar fraction exceeds 0.7 .

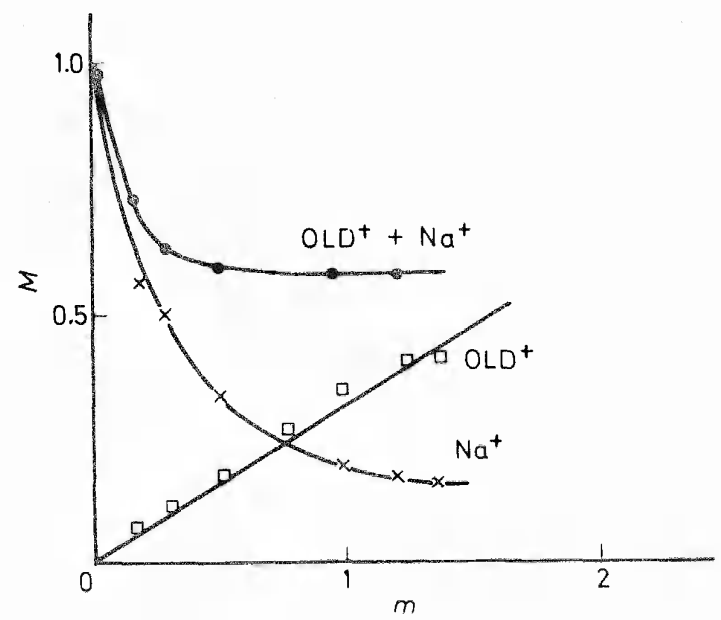

Figure 9. Transformation of a one-component system into a three-component system in oleandomycin sorption. $M$ is the molar ratio of ions in the sorbed state, $m$ is the quantity of sorbed oleandomycin meq $\mathrm{g}^{-1}$ of the carboxylic resin KFUKh.

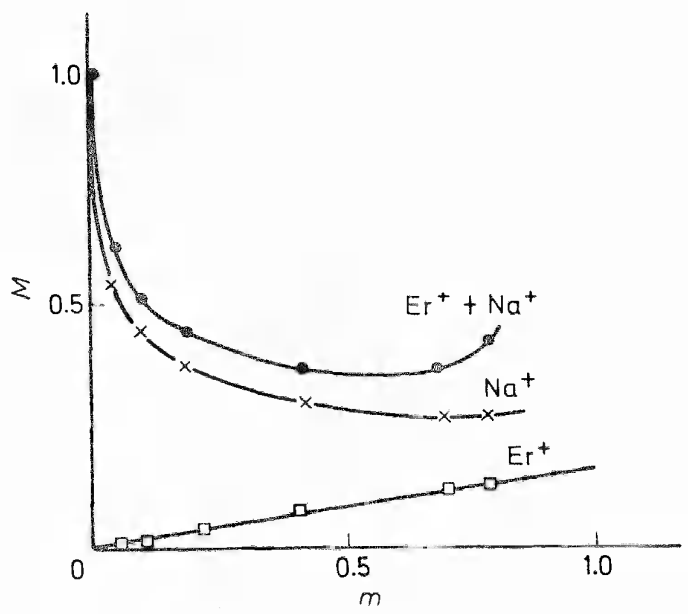

Figure 10. Transformation of a one-component system into a three-component system in erythromycin sorption. $M$ is the molar ratio of ions in the sorbed state, $m$ is the quantity of sorbed erythromycin $\left(\mathrm{meq}^{-1}\right)$. 
Additional interaction is of great importance and determines the high selectivity of sorption of organic ions which for specially synthesized ion exchangers attains a tremendous value, of an order of magnitude of $10^{2}-10^{3}$. Nevertheless, as shown by the term itself, this interaction is only an additional effect operative when the electrovalency interaction appears. In crosslinked polyelectrolytes in the course of organic ion sorption electrovalency interaction acquires particular properties determined by changes in the dielectric permittivity of the medium. Figures 9 and 10 show that sorption of antibiotics -oleandomycin and erythromycin-on the Na-form of carboxyl resins proceeds with simultaneous desorption of a more than equivalent amount of sodium as a result of changes in hydrogen-sodium exchange and of progressive replacement of sodium ions by hydrogen ions in the exchanger. although the process occurs at neutral $\mathrm{pH}$. Changes in the degree of ionization of carboxyl groups in crosslinked polyelectrolytes in the presence of organic ions was also proved by direct titration of ion exchanger by organic bases.

\section{INTERACTION OF CROSSLINKED POLYELECTROLYTES WITH PROTEINS (SORPTION AND CHROMATOGRAPHY)}

Interaction of bipolar ions with polyelectrolytes, first of all with polyacids of the crosslinked type, i.e. with ion exchangers, has been studied in detail. Many relationships in these systems, in particular the part played by the additional interaction. the increase in entropy at high selectivity of sorption. the appearance of the cooperative effect and the shift of equilibrium for mineral ions by sorption of organic ions, are to a certain extent similar to general dependences for which the sorption of quaternary ammonium bases and ions of antibiotics serve as examples.

Monoaminomonocarboxylic amino acids at $\mathrm{pH}$ nearly 7 are sorbed by cation exchangers as cations, i.e. the formation of cations from bipolar ions occurs in the course of their sorption ${ }^{23}$. This type of process is more difficult for dipeptides, tripeptides and even more so for tetrapeptides: as a result they are less sorbed by the salt forms of cation exchangers. These dependences were applied to proteins for which it was also shown that sorption by cation exchangers is a specific phenomenon determined by the isoelectric state of the proteins and the state of their local dipolarity ${ }^{24}$. The possibility of the specific sorption of proteins including enzymes permitted the development of methods for their separation by using high capacity sorption (up to many hundreds of milligrams of proteins per gram of sorbent). These processes might be carried out not only analytically but also on a large scale and even industrially. For solving these problems it was necessary to abandon the inert matrices which are used in Sephadexes, biogels and their ion exchange variants. It is known, however, that the sorption of proteins by ion exchangers usually proceeds at a low sorption capacity owing to insufficient permittivity of the network of the ion exchanger, and is irreversible or occurs with partial or complete denaturation resulting from strong intermolecular action. For this reason, if we wished to develop sorption processes of high capacity for protein separation, it was necessary to synthesize and to use highly permeable crosslinked polyelectrolytes capable of reversible interaction with the protein macromolecules. In this work we proceeded from the assumption that the 


\section{G. V. SAMSONOV}

irreversible interaction and denaturation of proteins in this case are largely due to a combination of high free energy of interaction with the ability of the polyelectrolyte network to undergo deformation. An important stage of this work was the preparation and use of crosslinked polyelectrolytes undergoing little deformation and at the same time highly permeable and accessible to the diffusion of macromolecules. The use of a small amount of a crosslinking agent could not give good results since the networks of slightly crosslinked polyelectrolytes undergo great deformation when the $\mathrm{pH}$ of the solution and the ionic strength are changed, i.e. under usual working conditions. We achieved the best results by using triazine, that is a monomer containing three vinyl radicals, as a crosslinking agent. In combination with acrylic acids we obtained crosslinked polyelectrolytes of the carboxylic type which undergo little deformation even when the degree of ionization of carboxyl groups changes ${ }^{25-28}$. As shown in Figure 11, for protease of



Figure 11. Desorption of proteolytic enzyme (terrylitine) from Biosorb-KMT. $A$ is enzyme desorption $(\%) ; n$ is the ratio of swelling of the Na-form of Biosorb-KMT to swelling of the $\mathrm{H}$-form.

microbic origin the degree of desorption from such a crosslinked polyelectrolyte essentially depends on the ratio of the degrees of swelling in the $\mathrm{Na}$ - and $\mathrm{H}$-forms. Only when this value tends to unity is an almost quantitative yield in enzyme attained during desorption. Common highly swelling and slightly crosslinked carboxylic cation exchangers are characterized by the ratio of swelling exceeding 2 or even 3 . Under certain conditions the yield of the polyelectrolyte used dropped below 10 per cent. Naturally, the transition to more inert matrices decreases the degree of irreversible sorption of proteins and at the same time decreases the selectivity and capacity of sorption in the presence of competing ions.

Conditions for separating proteins on a carboxylic crosslinked polyelectrolyte undergoing slight deformation are determined by the dependence of the sorption capacity on $\mathrm{pH}$ and the ionic strength of solution (Figures 12 and 13). The left-hand branch of the sorption curves in Figure 12 is determined 


\section{SPECIFICITY OF INTERMOLECULAR ACTION}

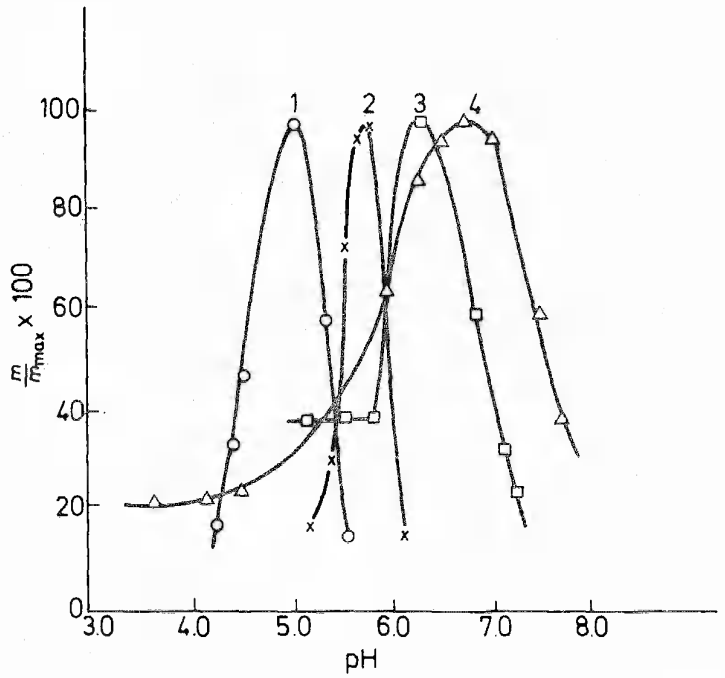

Figure 12 . Sorption capacity of proteins on Biosorb-KMT versus pH of the equilibrium solution. $\mathrm{m} / \mathrm{m}_{\max }$ is the ratio of the sorption capacity to the maximum capacity: 1. thermolysine. $m_{\max }=650 \mathrm{meq} \mathrm{g}^{-1} ; 2$. serum albumin, $m_{\max }=580 \mathrm{meq} \mathrm{g}^{-1} ; 3$. chymotrypsinogen, $m_{\max }=330$ meq $\mathrm{g}^{-1} ; 4$. ribonuclease, $m_{\max }=230 \mathrm{meq} \mathrm{g}^{-1}$.

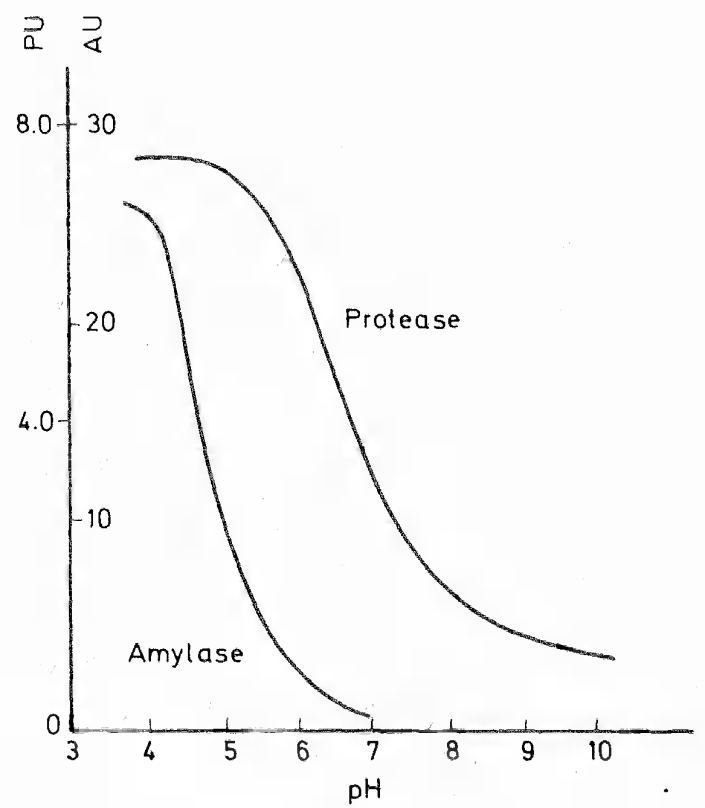

Figure 13. The right-hand branches of sorption curves for protease and amylase from Asperg. terricala on Biosorb-KMT. PU Proteolytic units: AU amylolytic units. 


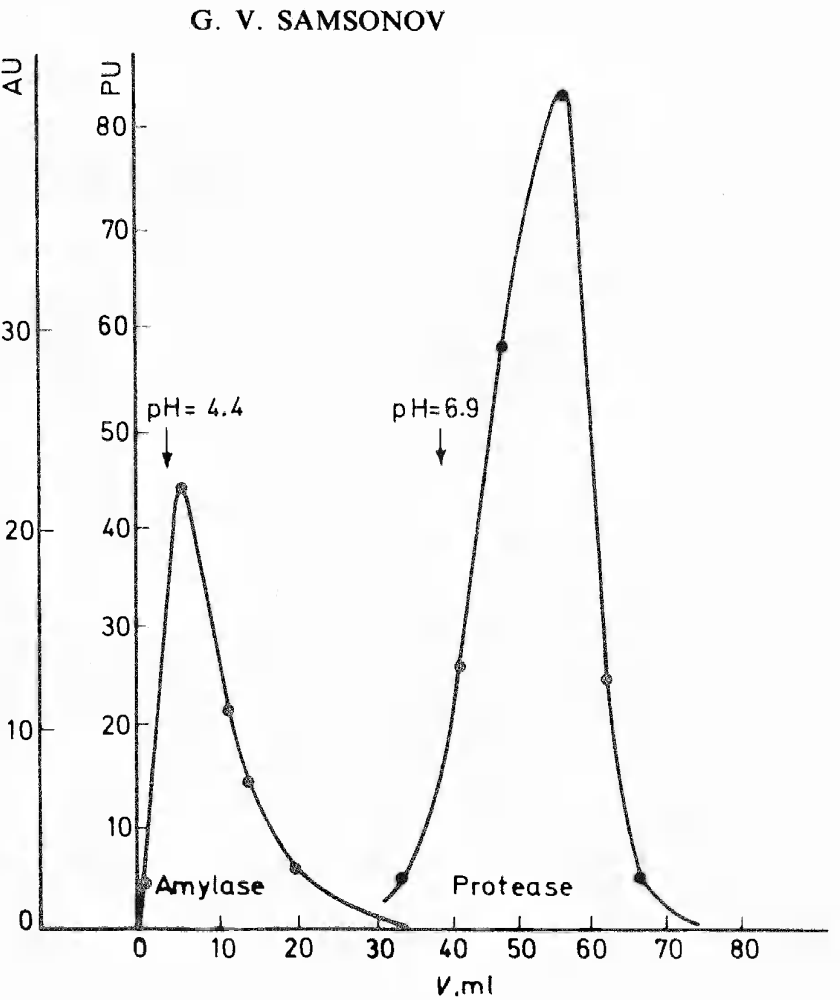

Figure 14. Fractionation of protease and amylase on Biosorb-KMT. PU Proteolytic units $\mathrm{AU}$ amylolytic units.

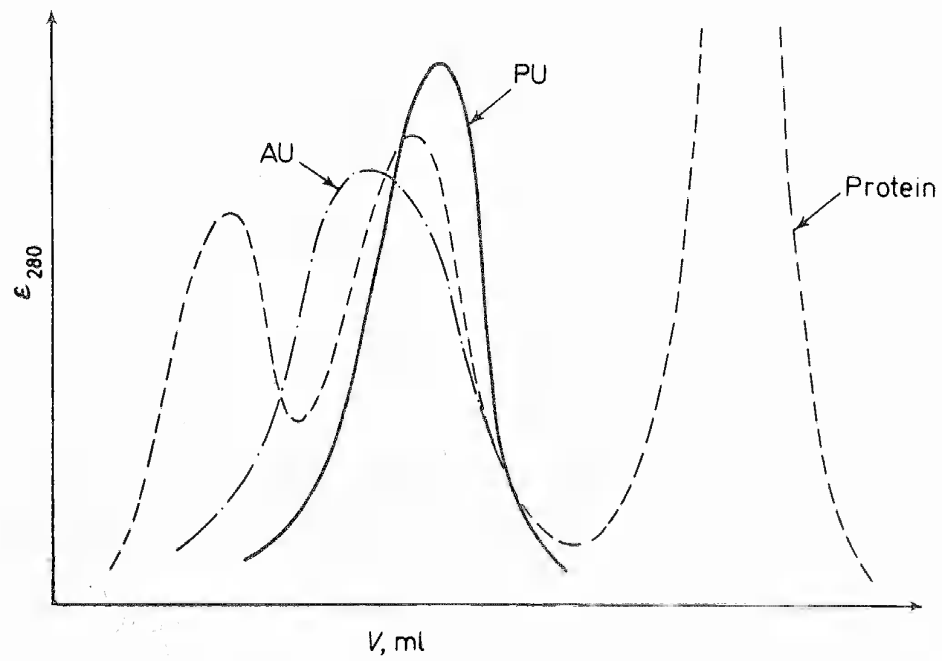

Figure 15. Gel chromatography of protease and amylase on Sephadex G-50. PU Proteolytic units: $\mathrm{AU}$ amylolytic units. 
mainly by the competition with hydrogen ions and often lies in the region of protein denaturation. For selecting the conditions of separation it is advisable to use the right-hand branch: its run is governed by the competition with cations in solution, in our case with sodium ions. Two microbic enzymesprotease and amylase - with very little difference in molecular weight ( $M=$ 26800 and 29000 , respectively) and in their isoelectric points ( $\mathrm{pI}=4.6$ and 4.2) exhibit quite different sorption curves (Figure 13). This is due to differences in their interaction with polyelectrolytes because this interaction depends not only on the charge of the macromolecules but also on local bipolarity and on all the combined effects of additional interaction.

All these sorption properties made possible complete separation of enzymes on a carboxylic crosslinked polyelectrolvte undergoing little deformation (Figure 14) whereas the standard methoc using Sephadex G-50 led only to partial separation (Figure 15). It should also be noted that the Sephadex column is of $1 \mathrm{~m}$ height while the height of the carboxylic polyelectrolyte in



Figure 16. Chromatographic separation of cellulase and pectinase from Asp. avamori on BiosorbKMT. $A$ activity (units $\mathrm{ml}^{-1}$ ). Sorption capacity $-40 \mathrm{mg}$ of pectinase on $1 \mathrm{~g}$ of sorbent.

the column is only $5 \mathrm{~cm}$. It is of particular importance that this small column separates a 10-fold amount of enzymes compared to the first column.

Hence, the efficiency of the sorbent operating on the principle of selective sorption is hundreds of times greater than the efficiency of gel chromatography. Finally, the time of experiments is also several times shorter. We used this principle of protein separation for various enzymes. Thus, Figure 16 shows the separation of cellulase and pectinase.

The second possibility of reversible selective ion exchange sorption and 


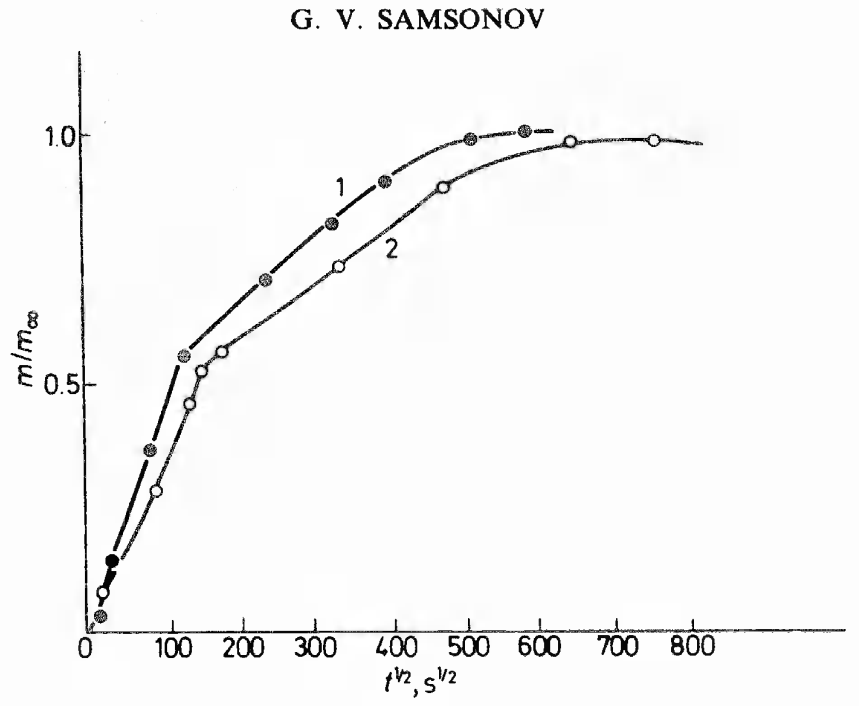

Figure 17. Kinetic curves of insulin (1) and lysozyme (2) sorption on macroporous sulpho cation exchanger $\mathrm{KU}-23 . \mathrm{m} / \mathrm{m}_{\infty}$ ratio of sorption capacity to limiting capacity; $t$ time (s).

protein chromatography consists in using macroporous resins obtained by copolymerization of monovinyl monomers in the presence of large amounts of of a divinyl compound in an organic solvent. Our main experiments were carried out with a sulphostyrene copolymer containing 30 per cent of divinylbenzene and showing a channel structure in the dehydrated state ${ }^{29.30}$. This sorbent exhibits high internal porosity and an internal surface of about $70 \mathrm{~m}^{2} \mathrm{~g}^{-1}$ with a pore diameter of up to $80 \AA$. For many macromolecules protein sorption occurs in two stages : the first stage proceeds at a high rate and the internal surface is filled with a monomolecular layer of macromolecules (Figure 17). In this stage the diffusion coefficient is $10^{-9} \mathrm{~cm}^{2} \mathrm{~s}^{-1}$. Then the sorption of proteins proceeds less intensively and the diffusion coefficient

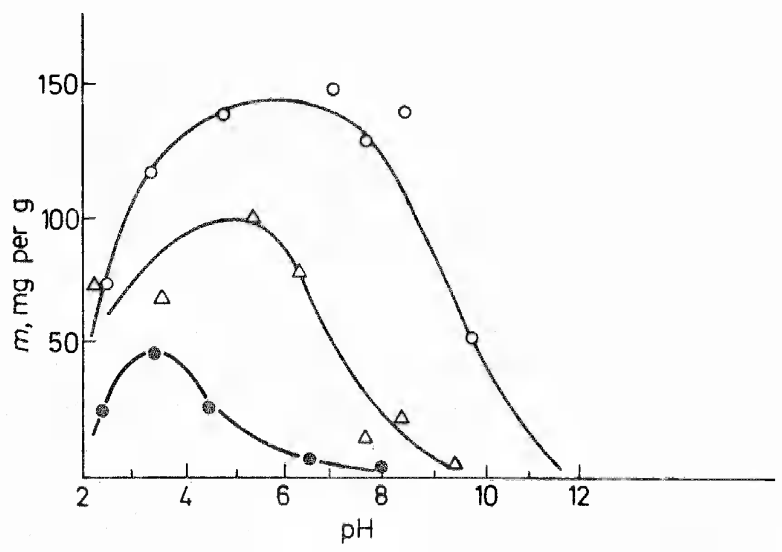

Figure 18. Capacity of protein sorption on macroporous sulpho cation exchanger K U-23 versus $\mathrm{pH}$ of solution. 1 Lysozyme; 2 chymotrypsinogen ; 3 serum albumin. 
decreases to $10^{-10}$ to $10^{-11} \mathrm{~cm}^{2} \mathrm{~s}^{-1}$. The selectivity also decreases: this is indicated by a decrease in the slope of the sorption isotherm. The upper point of the linear portion of the isotherm (Figure 17) agrees reasonably with the sorption capacity calculated for monomolecular filling of the sorbent proceeding from the value of internal surface.

For these resins the dependence of the sorption capacity on the $\mathrm{pH}$ of the solution is represented by a bell-shaped curve just as for carboxylic crosslinked rigid polyelectrolytes (Figure 18). The one-stage process of column sorption and desorption of insulin on a macroporous sorbent with pancreatic extract as the initial material yields a highly purified product (Figure 19). Crystallization of insulin may be carried out directly from the eluate ${ }^{31}$.

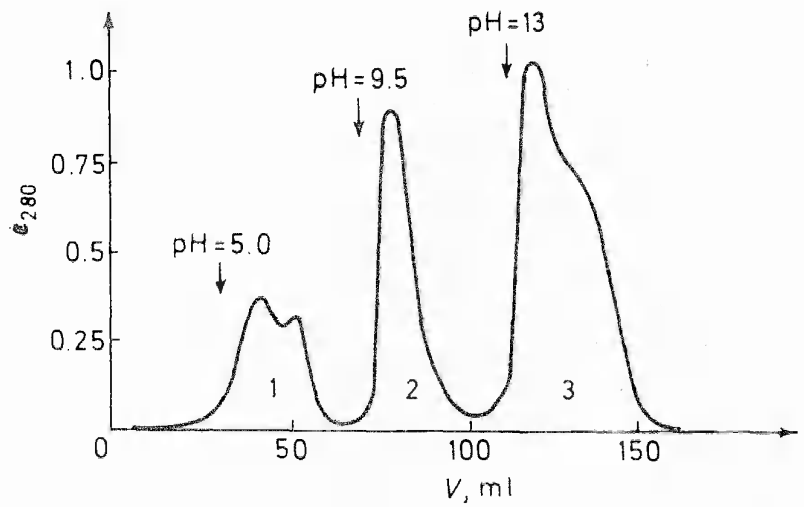

Figure 19. Chromatographic isolation of insulin from pancreatic extract on macroporous sulpho cation exchanger KU-23. 2 Insulin; 1,3 impurities. Elution by buffer solutions, $\mathrm{pH}=5.0$ :

9.5 and 13 .

\section{REVERSIBLY DISSOCIATING COMPLEXES OF PROTEINS WITH SOLUBLE SYNTHETIC POLYELECTROLYTES}

Ion exchange interactions in solutions of systems including physiologically active substances and synthetic polyelectrolytes are not only of theoretical significance. They can be used in practice for modification of physiologically active substances, for their stabilization (which is very advantageous, e.g. for enzymes and protein hormones) and for preparation of new types of medicines, such as those administered orally or having a prolonged action. Enzymes modified with the aid of synthetic polymers including soluble polymers are also used in industry.

Protection of insulin against the action of proteases and the acidity of the medium with retention of hormonal activity is made possible by the formation of a complex with polymethacrylic acid ${ }^{32,33}$. Gel chromatography of this complex after using pepsin and trypsin for degrading (Figure 20) shows that one native component in the complex is retained while incubation of unprotected insulin with the same enzymes under the same conditions results in a marked degradation of the hormone. A direct determination of the activity confirms this statement. The formation of reversibly dissociating complexes of trypsin with soluble polybases leads to stabilization of the 
G. V. SAMSONOV

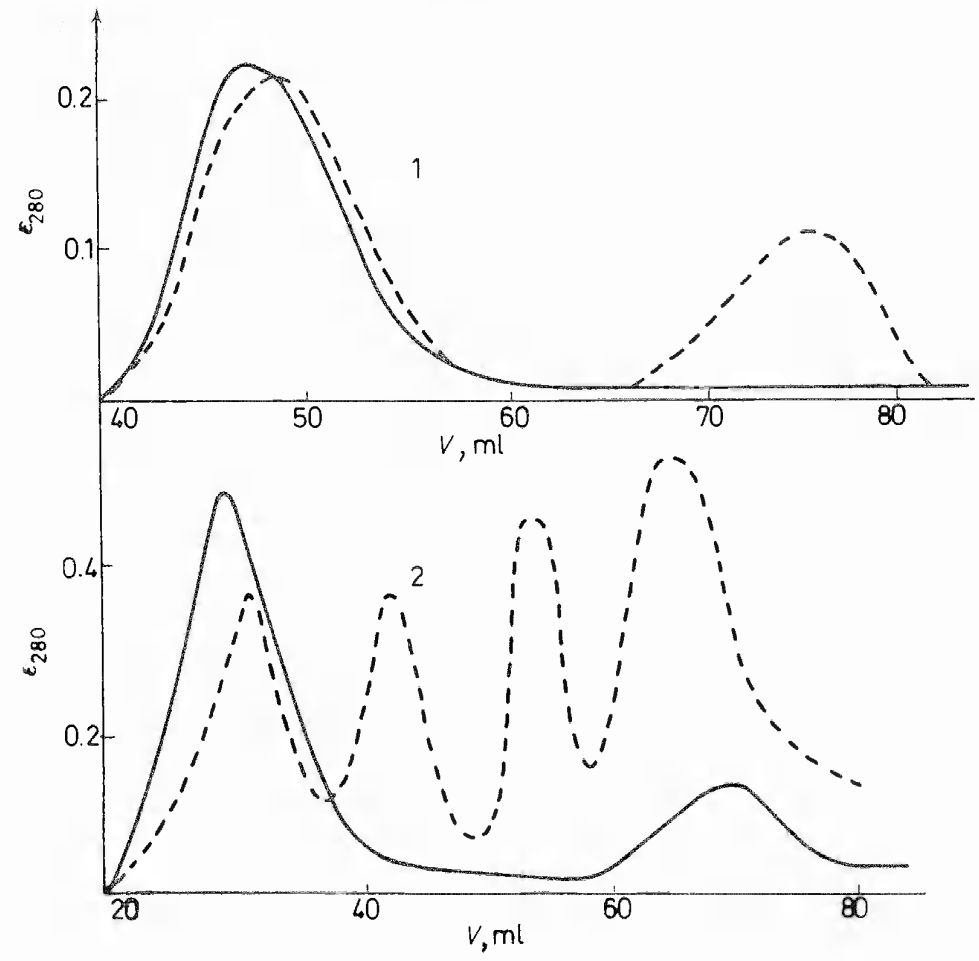

Figure 20. Gel chromatography of hydrolysis products for insulin-polymethacrylic acid complex by trypsin (1) and pepsin (2). Insulin, ----; complex,

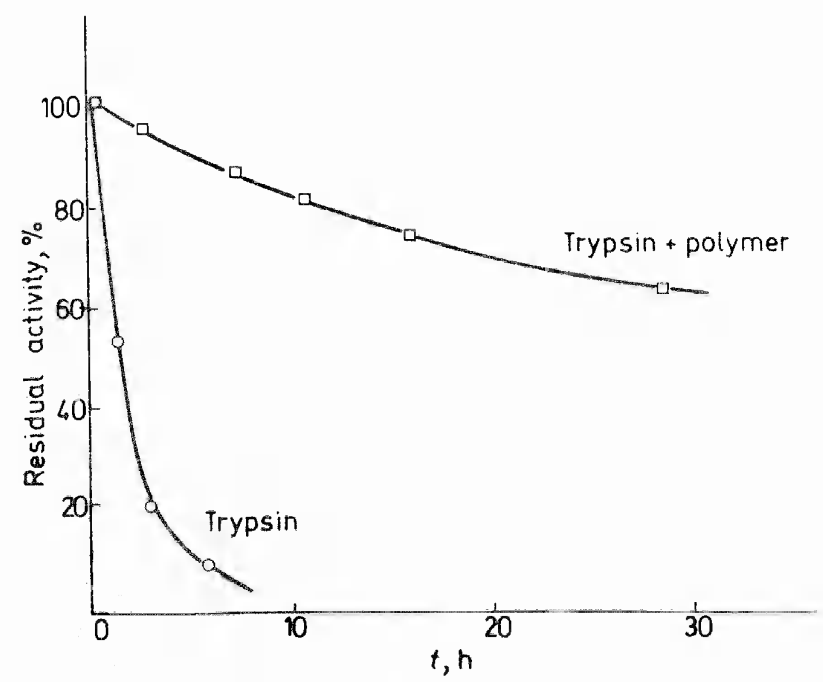

Figure 21 . Stability of a trypsin complex with poly(vinyl- $N$-imidazole). 


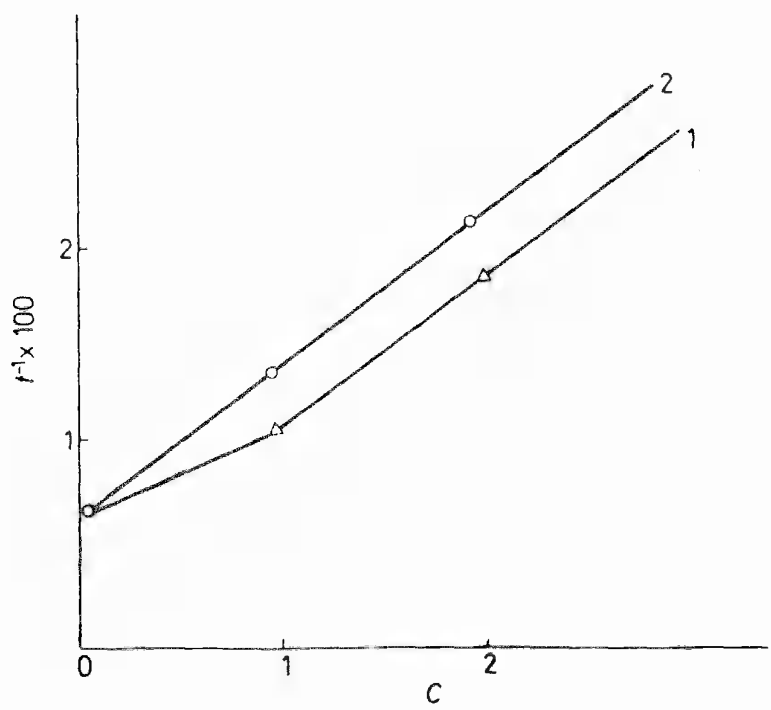

Figure 22. Rate of thrombin dissolution by trypsin in the presence of polybases. $t$ Time of dissolution of standard thrombi in min; $c$ concentration of polybases of two types ( 1 and 2 ) in $\mathrm{mg} \mathrm{m}^{-1}$. 1. Poly(vinyl-4(S)-imidazole); 2. poly(vinyl- $N$-imidazole).

enzyme (Figure 21). The stability of the $\mathrm{pH}$ value is also observed for these complexes. The value of the optical activity of the complex is retained over a wider $\mathrm{pH}$ range than in the initial trypsin (Figure 22). Moreover, this complex dissolves standard thrombi at a greater rate than native trypsin (Figure 23).

The peculiarities of reversible interaction in the formation of soluble molecular complexes (including polymer complexes) are usually studied by hydrodynamic, electrophoretic and chromatographic methods and also by investigating the membrane equilibrium or the kinetics of diffusion through membranes ${ }^{34-40}$. In particular, quantitative chromatographic analysis

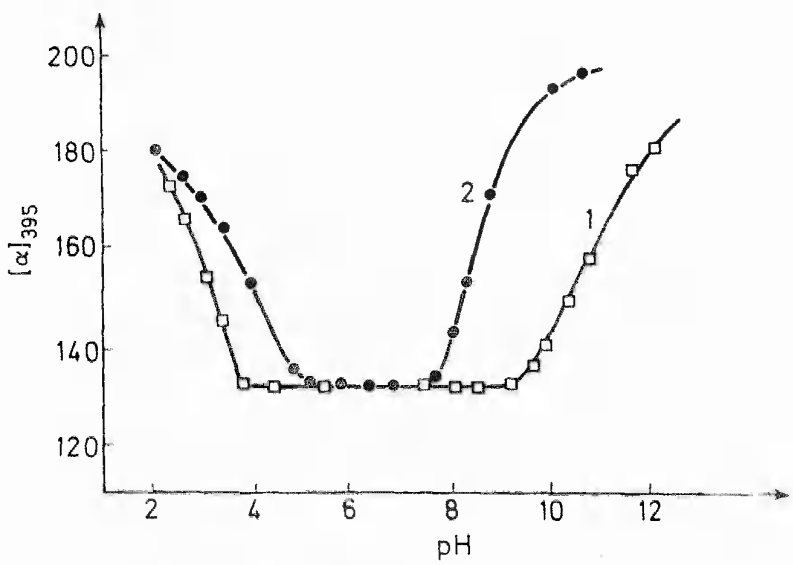

Figure 23. Optical activity of trypsin complex with poly(vinyl- $\mathrm{N}$-imidazole) versus $\mathrm{pH}$. Ionic strength $0.01 ; T=22^{\circ} \mathrm{C}$. 1 . Polymer + trypsin; 2 . trypsin. 


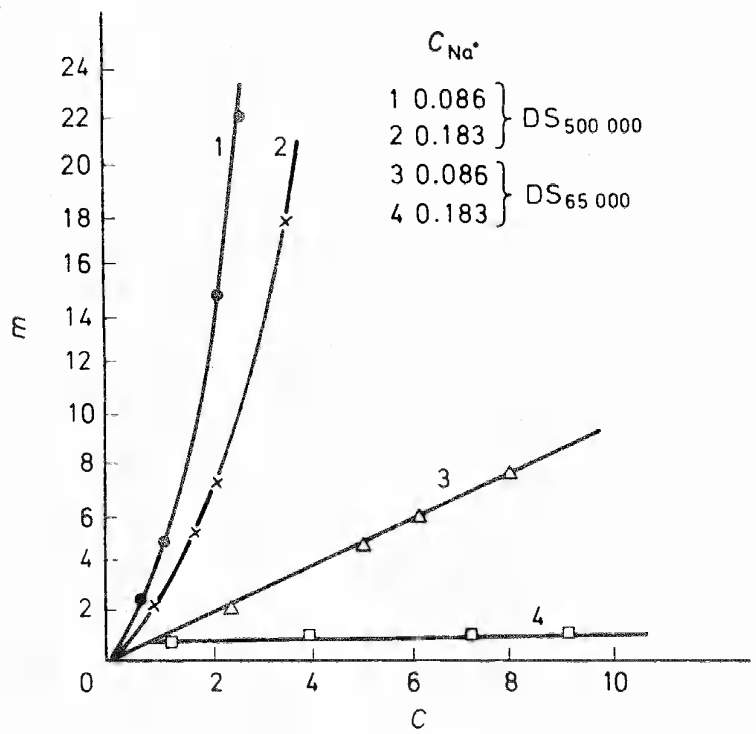

Figure 24. Isotherm of formation of a complex of ribonuclease with dextran sulphates, $m$ is the number of moles of RNAase in the complex per mole of dextran sulphates; $c$ is the concentration of RNAase in a free state in solution $\left(\mathrm{mol} \mathrm{ml}^{-1} \times 10^{5}\right)$ in initial concentration of dextransulphates $\left(1 \mathrm{mg} \mathrm{ml}^{-1}\right)$.

enables us to calculate both the equilibrium constants and the molecular ratios of the components of the complexes ${ }^{41-43}$.

It is of interest to study inhibition, stabilization and activation of pancreatic ribonuclease and desoxyribonuclease by soluble polymeric dextransulphates. As shown in Figure 24, one molecule of high molecular weight dextransulphate

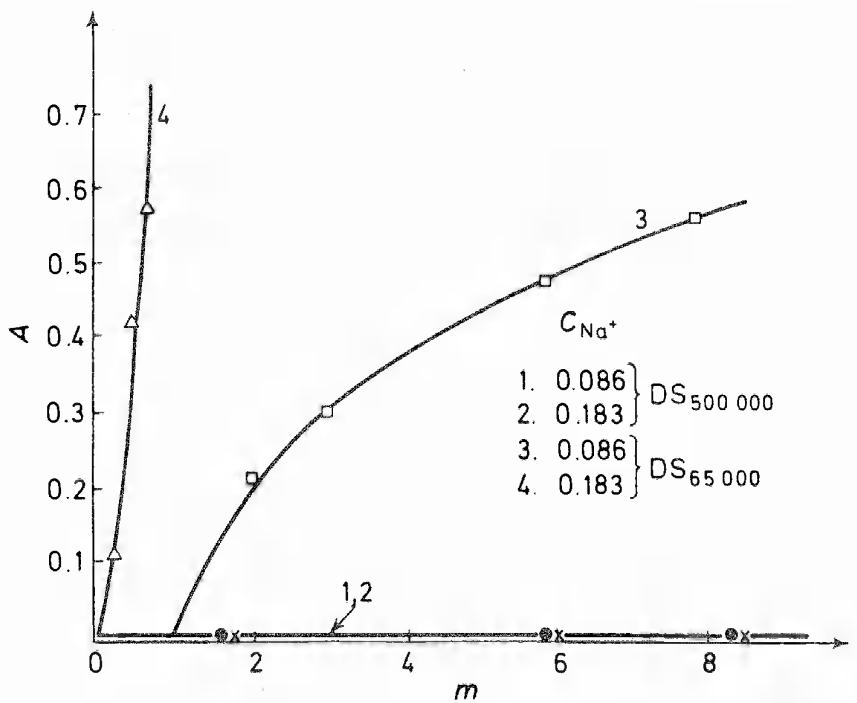

Figure 25. Specific activity $A$ of RNAase bonded in a complex with dextransulphates. $m=[$ RNAase $] /[\mathrm{DS}] ;$ substrate is uridine $2^{\prime} 3^{\prime}$-cyclophosphate. 


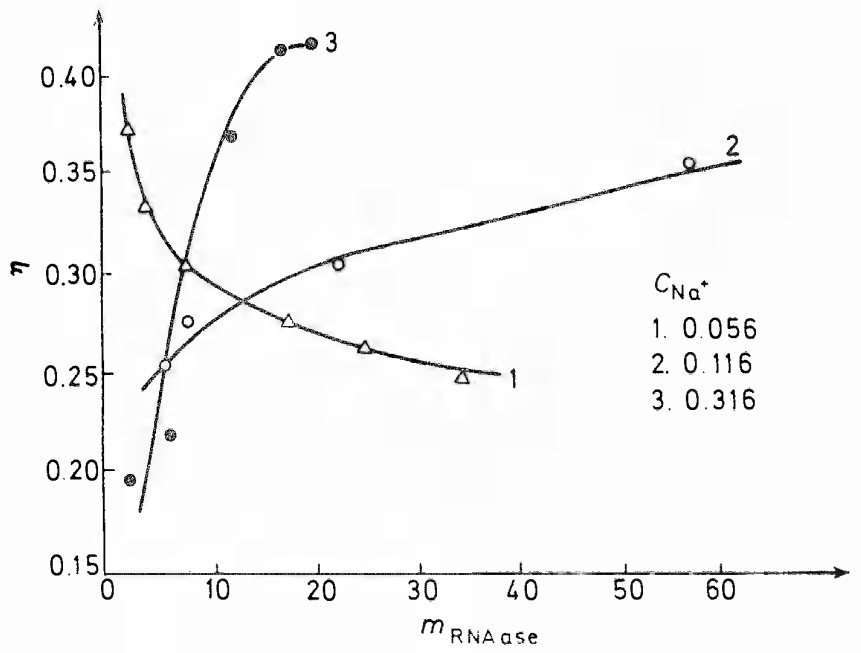

Figure 26. Viscosity of solutions of complexes of RNAase with dextransulphates. (M.W. 500000 ); $m_{\text {RNAase }}=[$ RNAase $] /[\mathrm{DS}] ; T=20^{\circ} \mathrm{C} ; \mathrm{pH}=7.0$.

$(M=500000)$ binds up to 20 molecules of enzyme whereas a dextransulphate of a relatively low molecular weight $(M=65000)$ binds a relatively small quantity of ribonuclease molecules, particularly when the ionic strength increases. In the first case the shape of isotherms for binding a large quantity of enzyme (the increase in the slope of the isotherm indicates the cooperative effect of binding) shows mutual interaction of molecules of RNAase fixed on

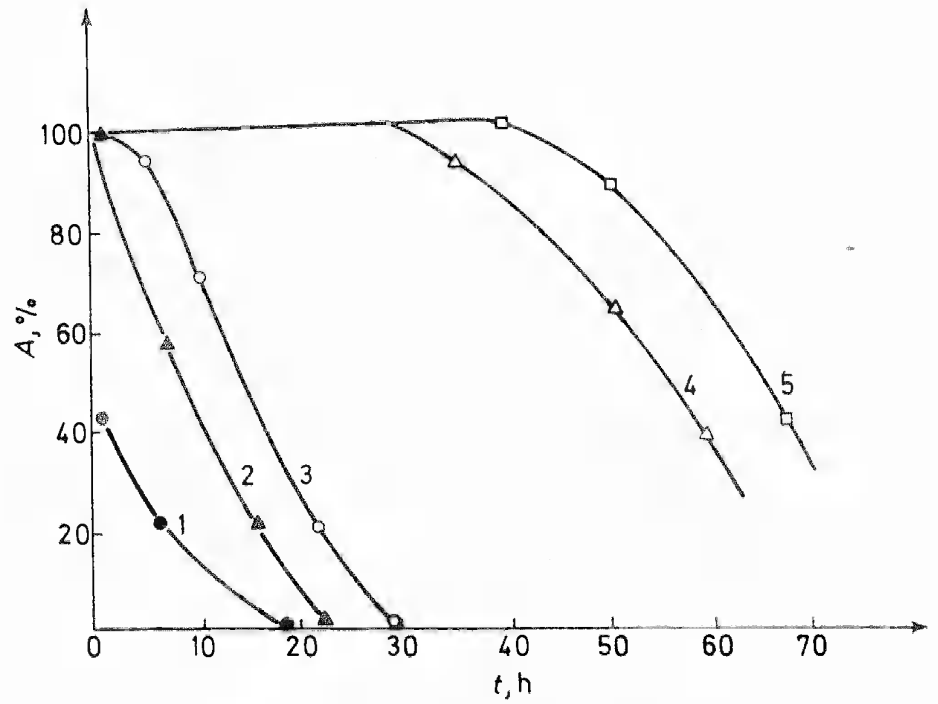

Figure 27. Stabilization of deoxyribonuclease by dextransulphates. $A$ is the activity of DNAase (measured for DNA from calf thymus). 1, DNAase $+\operatorname{DS}_{500000}(17 \% \mathrm{~S}) ; 2$, DNAase; 3, DNAase $+\operatorname{DS}_{50000}(17 \% \mathrm{~S}) ; 4$, DNAase $+\operatorname{DS}_{50000}(11 \% \mathrm{~S}) ; 5$, DNAase $+\operatorname{DS}_{50000}(8 \% \mathrm{~S})$. 


\section{G. V. SAMSONOV}

dextransulphate. The use of high molecular weight dextransulphate exhibiting the cooperative binding effect leads to the inhibition of RNAase, while the binding of enzyme by dextransulphate of a lower molecular weight results in an increase in the enzyme activity (Figure 25). It is also possible to develop conditions for its activation with an increase in the activity to 130 per cent with respect to the activity of native enzyme. Successive binding of RNAase by dextransulphate under conditions of cooperative interaction leads to a decrease in the viscosity of the solution whereas non-cooperative or slightly cooperative interaction increases the viscosity (Figure 26). The effect of the molecular weight of the polymer and of the number of ionogenic groups in polyelectrolytes on the peculiarities of interaction with enzymes is also apparent for desoxyribunuclease (Figure 27). Dextransulphates of relatively low molecular weight with a limited number of sulpho groups exhibit the stabilization of enzyme whereas high molecular weight polyelectrolytes with a large amount of sulpho groups inhibit DNAase. Both factors, i.e. the increase in the number of sulpho groups and the increase in the molecular weight of dextransulphate contribute to the cooperative effect of binding DNAase and its inhibition. In contrast, independent fixation of this enzyme on single active centres of polyelectrolyte leads to the stabilization of very labile pancreatic DNAase.

\section{ACKNOWLEDGEMENT}

The work described in this paper was carried out with the participation of L. V. Dmitrenko, B. V. Moskvichev, R. B. Ponomareva, L. K. Shataeva. N. N. Kuznetsova, D. I. Ostrovsky, A. A. Selezneva and R. V. Koltsova

\section{REFERENCES}

1 T. R. E. Kressman and J. A. Kitchener, J. Chem. Soc. 1208 (1949).

2 J. R. Millar, D. G. Smith, N. E. Marr and T. R. E. Kressman, J. Chem. Soc. 2740 (1964),

${ }^{3}$ A. Schwarz and G. E. Boyd. J. Phvs. Chem. 69. 4268(1965).

+ G. E. Boyd and O. V. Larsen, J. Amer. Chem. Soc. 89. 6038 (1967).

${ }^{5}$ G. V. Samsonov, B. V. Moskvichev, V. A. Pasechnik, C. B. Musabeckov, B. S Chak yna and N. M. Smirnova. J. Phys. Chem. (Russian) 44. 2589 (1970).

- G. V. Samsonov, B. V. Moskvichev and N. N. Kuznetsova, in lon Exchange and Ionexchangers. p. 90. Science publication of Academy of Sciences of the USSR (1970).

B. V. Moskvichev, N. N. Kuznetsova and G. V. Samsonov. J. Phys. Chem. (Russian) 45, 1873 (1971).

${ }^{8}$ B. V. Moskvichev and G. V. Samsonov, J. Phys. Chem. (Russian) 45, 1317 (1971).

9 B. V. Moskvichev and G. V. Samsonov. J. Phys. Chem. (Russian) 45, 1371 (1971).

10 G. V. Samsonov, S. F. Klich and D. N. Gulaeva, in lon Exchangers and lon-exchange, p. 91. Science publication of Academy of Sciences of the USSR (1965).

1 G. V. Samsonov and R. M. Bakaeva, Antibioticks, 737 (1968).

12 G. V. Samsonov. R. M. Bakaeva. S. S. Urusovit and L. A. Domracheva. Chem. Pharmaceutic J. (No. 7$) 28$ (1969).

13 G. V. Samsonov and L. V. Dimitrenko, in Thermodynamics of Ion Exchange, 178, Minsk, Science and Technology publication (1968).

${ }^{14}$ G. V. Samsonov, E. B. Trostianskaya and G. E. Elkin, Ion Exchange Sorption of Organic Substances Science publication of Academy of Sciences of the USSR (1969).

15 G. V. Samsonov. V. G. Vorobyeva and M. V. Kravetz. Colloid J. 427 (1970).

${ }^{16}$ L. V. Dmitrenko. A. D. Morozova. V. S. Pyrogov and G. V. Samsonov, High Molec Comp., 14, 353 (1972). 


\section{SPECIFICITY OF INTERMOLECULAR ACTION}

17 L. V. Dmitrenko, A. D. Morozova and G. V. Samsonov, Izvest. Akad. Nauk SSSR. 1563 (1972).

18 A. V. Michalev and G. S. Libinson, J. Phys. Chem. (Russian) 43, 1333 (1969).

19 A. V. Michalev and G. S. Libinson, J. Phys. Chem. (Russian) 44. 2887 (1970).

20 A. V. Michalev and G. S. Libinson, J. Phys. Chem. (Russian) 45, 2699 (1971).

21 A. Sh. Genedi and G. V. Samsonov, Kolloid J. (Russian) 31, 674 (1969).

22 L. V. Dmitrenko, A. D. Morozova and G. V. Samsonov, Izvest. Akad. Nauk SSSR, 1563 (1972).

23 G. V. Samsonov and N. P. Kuznetzova, Dokl. Akad Nauk SSSR, 115, 351 (1957).

24 G. V. Samsonov and R. B. Ponomareva, Biochem. (Russian) 24, 63 (1959).

25 L. K Shataeva, A. A. Selezneva, O. V. Orlyevskaya, D. I. Ostrovsky, V. V. Korshunov, R B. Ponomareva, N. N. Kuznetzova, K. P. Papukova and G. V. Samsonov, in Synthesis, Structure and Properties of Polymers, 225, Science publication of the Academy of Sciences of the USSR (1970).

26 A. A. Selezneva, G. A. Babenko, O. V. Orlyevskaya and G. V. Samsonov, Microbiol. Industry, 14 (1972).

27 Pat. USSR, N322332, 17.7,1970. Bull. Izobret. N36 (1971).

28 O. V. Orlyevskaya, L. K. Shataeva and G. V. Samsonov, Appl. Biochem. Microbiology. (Russian) 7, 1971 (1971).

29 D. I. Ostrovsky. A. D. Morozova. L. V. Dmitrenko. P. D. Kozlova and G. V. Samsonov, Izvest. Akad. Nauk SSSR, ser. chem. 1214 (1972).

30 L. V. Dmitrenko, D. I. Ostrovsky and G. V. Samsonov, High Molec. Comp. 14. 859 (1972).

31 Pat. USSR, N213256, J0.5.1963, Bull. Izobr. N10(1968).

32 M. V. Glykina, N. N. Kuznetzova, I. A. Bolotina and G. V. Samsonov, Molec. Biology, 4, 692 (1970).

33 M. V. Glykina, N. P. Kuznetzova, S. V. Koltzova and G. V. Samsonov, Biochemistry(Russian), 36, 258 (1971).

34 G A. Gilbert, Proc. Roy. Soc. A250, 377 (1959).

35 G. A. Gilbert, Nature, 212, 296 (1966).

36 R. Towner, J. Winterbottom and S. W. Timasheff, J. Amer. Chem. Soc. 82, 3161 (1960).

37 H. Noguvh, Biochem. Biophys. Acta, 22, 459 (1956).

38 G. K. Ackers and T. E. Tompson, Proc. Nat. Acad. Sci., USA, 53, 342 (1965).

39 D. J. Winsor and H. A. Scheraga, Biochemistry, 2, 1263 (1965).

40 G. K. Ackers, J. Biol. Chem. 242, 3026 (1967).

41 G. V. Samsonov and R. B. Ponomareva, Biofizika, 13, 213 (1968).

42 G. V. Samsonov, R. B. Ponomareva and R. G. Luchko, Biofizika, 14, 634 (1969)

43 G. V. Samsonov and R. B. Ponomareva, Studia biophysics, 24/25, 399 (1970). 